\title{
Approaches In The Treatment of Urethral Strictures
}

\author{
Murat Demir $^{1^{*}}$, Kerem Taken $^{2}$ \\ ${ }^{1}$ Department of Urology, Ministry Of Health University Van Training And Research Hospital, Van, Turkey \\ ${ }^{2}$ Department of Urology, School of Medicine, Yuzuncu Yil University, Van, Turkey
}

\begin{abstract}
Urethral strictures are defined as the narrowing of the anterior urethral lumen or as corpus spongiosum fibrosis. Anterior urethral strictures can be divided as iatrogenic, inflammatory, idiopathic, and traumatic based on their etiology. Lower urinary tract septomas develop as a result of this disease. Many complications may occur in untreated patients.Cystoscopy, retrograde urethrography and ultrasonography can be used to diagnose the disease.Treatment methods are endoscopic and open surgery.Endoscopic treatment methods include dilatation, cold knife and laser internal uretrotomy. Recurrent bulbar urethral strictures; "End-to-end anastomosis urethroplasty" technique for short stenosis shorter than $2 \mathrm{~cm}$. The technique of like ogmented anastomosis urethroplasty an with buccal graft is used for longer or complicated stenosis.
\end{abstract}

Key Words: Urethra, stricture, urethroplasty

\section{Introduction}

Urethral strictures are defined as the narrowing of the anterior urethral lumen or as corpus spongiosumfibrosis (spongiofibrosis) formed by intense collagen and fibroblast deposition (1). This fibrosis can be limited to the spongious tissue orcan also extend into the tissues outside of the corpusspongiosum as well. Contraction of the fibrotic tissueleads to the narrowing of the urethral lumen, thereby resulting in urinary obstruction and retention. Unless treated, it may also lead to complications including urinary tract infections, neurogenic bladder, and renal failure (1).

Male urethra consists of prostatic, membranous, bulbar, and penile urethra and fossa navicularis. The posterior urethra includes the prostatic and membranous urethra while the anterior urethra includes the remaining parts. World Health Organization (WHO) limits the definition of stricture to the anterior urethra and proposes the use of terms 'contracture'and'stenosis' for the posterior urethra (13).Although urethral strictures can be seen in the entire anterior urethra, they mostly occur in the bulbar urethra $(46 \%)(4,5)$.

Literature indicates that the first description of urethral stricture dates back to ancient times. In $600 \mathrm{~s}$ $\mathrm{AD}, \quad \mathrm{a}$ well-known Indian surgeon namedSushrutaprovided information on the anatomy of urethra and described urethral dilatation in a Sanskrit text known as SushrutaSamhita. In his urethral dilatation method, Sushruta dilated the urethra by inserting rods of increasing thickness $(6,7)$.
The incidence of urethral strictures has been shown to be as high as $0.2-1.2 \%$ and to be higher in men aged over 55 years.

Etiology: Anterior urethral strictures can be divided as iatrogenic, inflammatory, idiopathic, and traumatic based on their etiology. In a previous meta-analysis, Fenton et al. reported that most of the strictures were idiopathic (34\%) and iatrogenic (32\%). The authors also noted that the iatrogenic strictures mostly involved the bulbar urethra and the inflammatory strictures mostly involved the penile urethra and fossa navicularis (8). Lumen et al. evaluated 268 patients by dividing the patients into two groups as patients aged below and over 45 years. The authors revealed that the most common strictures were idiopathic strictures in patients aged below 45 years as opposed to iatrogenic strictures in patients aged over 45 years. The authors also noted that iatrogenic strictures mostly occur secondary to urethral catheterization, prostatectomy, cystoscopy, and hypospadias repair in advanced-age patients while idiopathic strictures often occur in adolescents and young men (9). On the other hand, although infections, which are classified as inflammatory causes of strictures, were the most common cause of strictures in the past, they have become relatively less common due to the advancements in treatment methods. In particular, urethritis was responsible for $40 \%$ of all urethral strictures in 1960s. However, although gonorrheal urethritis is known to cause urethral stricture, the role of chlamydial urethritis in the development of urethral stricture remains unclear (5-9).

Clinical Presentation: Urethral stricture is characterized by restricted urine flowca used by the 
narrowing of the urethral lumen. Patients initially present with split urine stream during micturition and post-micturition dribble. As bladder contraction is obstructed by the stricture, the detrusor muscle attempts to push more strongly so as to overcome the obstruction, thereby leading to thickening of the bladder wall. After a certain period of time, bladder diverticula and neurogenic flask bladder may occur, which may even lead to kidney failure. On the other hand, patients may also present with urinary tract infections, orchitis, and bladder calculi. For these reasons, urethral strictures should be suspected in patients younger than 65 years of age presenting with lower urinary tract symptoms (10-11). In particular, patients with a history of urethral endoscopic surgery, urethral catheterization, urethritis, and trauma should be examined more closely (11).

Diagnosis: Patients with symptomatic urethral strictures typically present with obstructive symptoms. Physical examination often reveals no significant signs while patients in the advanced stage can present with a palpable mass associated with spongiofibrosis around the anterior urethra. The first step in the diagnosis of patients suspected with urethral stricture includes complete urine examination, uroflowmetry, and post-micturition residual volume measurement. The maximum flow rate on uroflowmetry is $20-25 \mathrm{ml} / \mathrm{sec}$ in men and 25 $30 \mathrm{ml} / \mathrm{sec}$ in women. Urethral strictureslead to a decreased flow rate witha plateau pattern. Therefore, patients younger than 65 years of age with a maximum flow rate of lower than $12 \mathrm{ml} / \mathrm{sec}$ should be suspected with urethral stricture (12-14). Urethral strictures can be diagnosed by cystoscopicand sonographic techniqueswithradiopaque imaging agents (15) (Figure-1). Although cystoscopy can be used for establishing the diagnosis and determining the exact localization of the stricture, it remains inadequate inthe determination of the length of the stricture and the severity of fibrosis. To determine the length of the stricture, radiographic techniques such as retrograde urethrographyand voiding cystourethrography can be used. In particular, retrograde urethrography has become the golden standard in the diagnosis of urethral stricture (16) (Figure-2). Though rarely, ultrasonography (USG) is also used for the determination of the localization and length of the stricture and the severity of fibrosis and for precisemeasurement ofpost-micturition residual volume $(15,16)$ (Figure-3).

\section{Treatment}

1-Dilatation: Dilatation is the oldest known treatment for urethral stricture.In 600s AD, urethral dilatation was performed with rods of increasing thicknessin India (5), primarily to achieve re- epithelialization of the urethra prior tofibrosis formation. Today, however, urethral dilatation can be performed with a balloon, filiform, and selfcatheterization. Of these, balloon dilatation has been shown to be the safest technique $(17,18)$. The reported success rates in the treatment of soft, primary strictures and strictures shorter than $1 \mathrm{~cm}$ vary between $50-70 \%$ (17). Moreover, the success rates in carefully selected patients treated with internal urethrotomy are similar. However, the studies that have compared these two approaches are not randomized studies but rely on retrospective analyses alone $(19,20)$.Nevertheless, despite their low success rates, these two approaches are commonly preferred by urologists as they can be administered with local anesthesia, havelow complication rates, and require no substantial experience.

2- Internal Urethrotomy: Internal urethrotomyinvolvesluminal dilatation withtransurethral resection of the fibrotic scar tissue (20). The fibrotic scar tissuemust be removed down to the healthy tissue, so that the healing occurs by secondary intention. If re-epithelialization occurs prior to fibrosis formation, the procedure is considered curative; if not, stricture willrecur. Literature indicates a wide range of success rates for internal urethrotomy, between $8 \%$ and $80 \%$.This wide range is associated with inappropriate classification of patients and the use of nonstandard criteria for the assessment of success rates (21-23). Dubey et al. showed an inverse relation between the severity of luminal stricture and the success rate of internal urethrotomy and reported that a stricture of $74 \%$ is associated with poor prognosis (24). SantucciveMcAninchreported a success rate of $20 \%$ for internal urethrotomy, whereas Pansadoro et al. reported a success rate of $35 \%$ and suggested that secondary procedures have no significant effect on the success rates ofinternal urethrotomy (25-26). Notwithstanding, the frequent use of internal urethrotomy by urologists is due to the scarcity of surgeons experienced in urethroplasty. On the other hand, someprevious short-term studies used holmium laser urethrotomy in lieu of cold knife urethrotomyto improve the treatment success of internal urethrotomy and reported that the treatment success did not differ and contrarily, the treatment costs increased (27). Similarly, Zheng et al. compared the use of cold knife and laser urethrotomy in 453 patients that underwent internal urethrotomy and reported that there was no significant difference between the two techniques with regard to treatment success and the patients that underwent laser urethrotomy had less hemorrhage and longer 


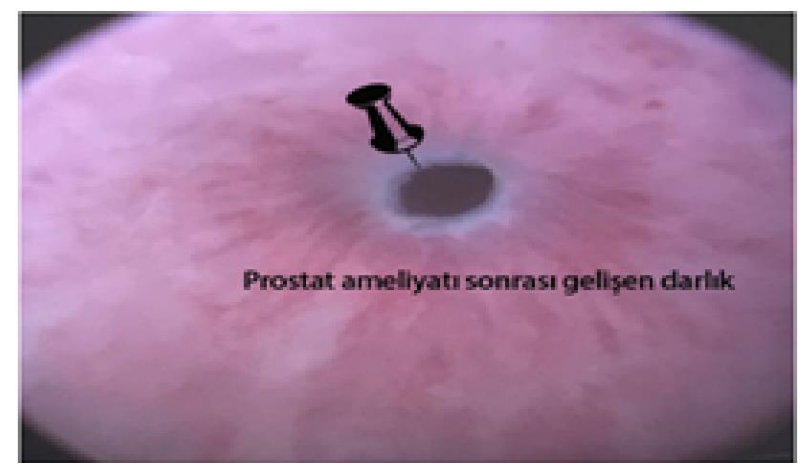

Fig. 1. Urethral stricture visualized on cystoscopy

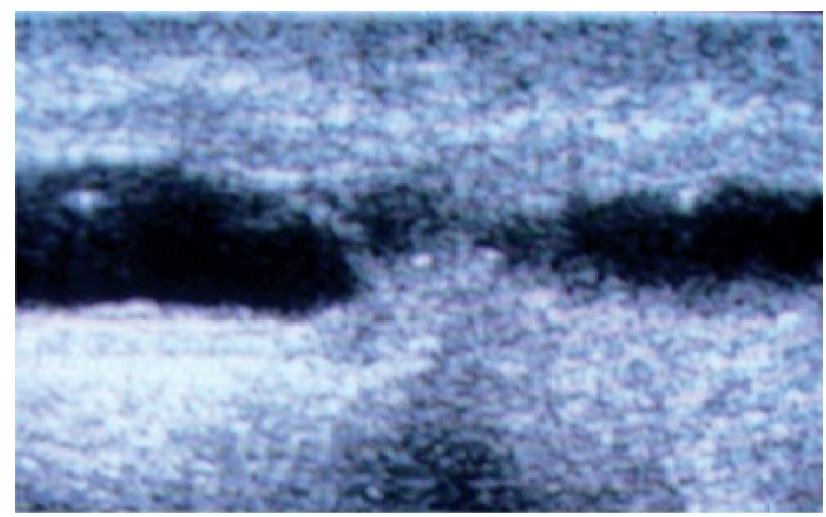

Fig. 3. Urethral stricture visualized on ultrasonography

operative times (28). On the other hand, there are some studies reporting on favorable outcomes provided by laser urethrotomy and suggesting that the administration of internal urethrotomy with intralesional injection of Vatsala-Santosh PGI triinject (triamcinolone, mitomycin $\mathrm{C}$, and hyaluronidase) can be useful for the prevention ofrecurrence $(29,30)$.

Urethroplasty: Urethroplasty is often preferred in cases recurring within three months following internal urethrotomy or recurring after two unsuccessful interventions, the cases that are unlikely to heal with additional endoscopic interventions $(31,32)$. Longterm success rates of urethroplasty have been reported to be as high as $85-90 \%$ (31-33). Pardeshiet al., for instance, reported a success rate of $95.2 \%$ in a series of 21 patients $(34,35)$. Due to these high success rates, urethroplasty is accepted as the golden standard in the treatment of urethral stricture (36-40). The urethroplasty techniques described in the literature include.

\section{a)Excision and Primary Anastomosis(EPA) b)Heineke-MikuliczStrictureplasty c)Augmentation Urethroplasty}

A) Excision and Primary Anastomosis (EPA): Excision and primary anastomosis (EPA), also known as end-to-end anastomosis, is often used in bulbar

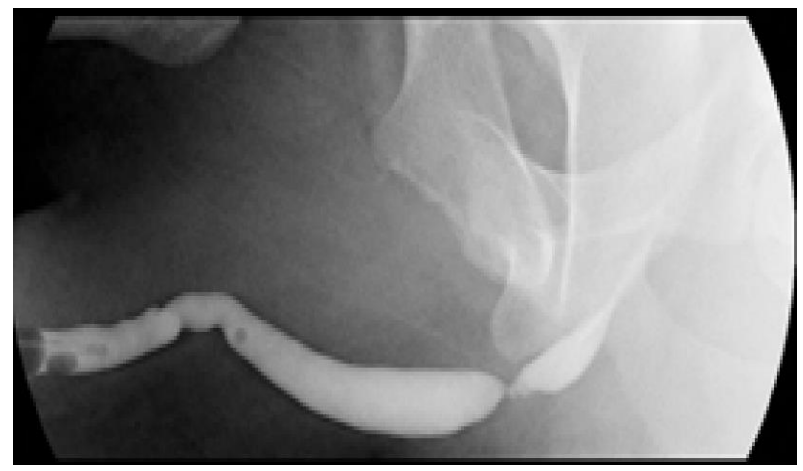

Fig. 2. retrograde urethrography
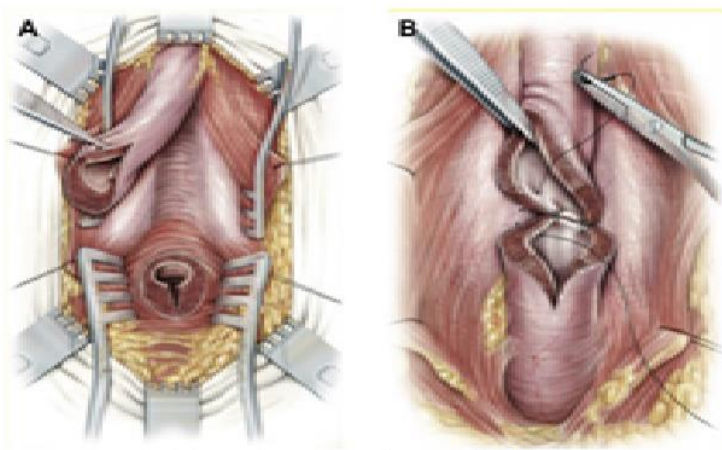

excision primary anastomosis(EPA)

Fig. 4. excision primary anastomosis

urethral strictures shorter than $2 \mathrm{~cm}$ and includes excision of the stricture segment as in end-to-end anastomosis, with reported success rates of $90-95 \%$ $(40,41)$. However, despite its high success rates, EPA is considered to increase the risk of sexual dysfunction (42). EPA is performed with the patient placed in the lithotomy position and a vertical midline incision made in the perineum. Following the division of the cutaneous and subcutaneous tissue and fascia, the bulbospongiosus muscle is encountered and is transected to expose the urethra. Subsequently, the urethra is mobilizedfrom the surrounding tissues and after determining the extent of the stricture, the fibrotic tissue is transected at the level of the stricture and dissected until healthy mucosa is reached. Ultimately, both ends of the urethra are widely spatulated and then absorbable sutures are placed from mucosa to mucosa, i.e. from spongious tissue to spongious tissue (41). Although EPA is recommended for strictures shorter than $2 \mathrm{~cm}$, Morey et al. showed that it can be used for strictures of up to $5 \mathrm{~cm}$ (42). In patients with long urethral stricturesthe corpus cavernosum can be split (corporoseparation) to relieve urethral tension by shortening the distance between the two ends. However, if urethral tension persists after splitting, the distance can be shortened by removing the inferior portion of pubis (40-42) (Figure-4). 

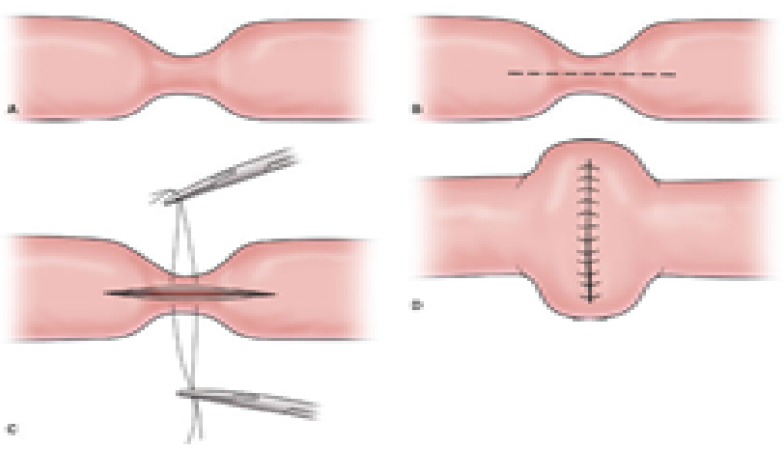

Fig. 5. Heineke Mikulicz

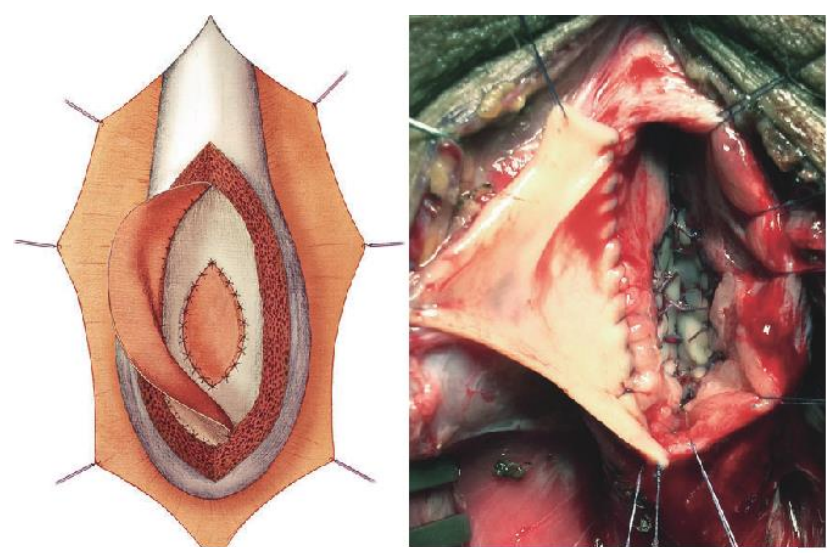

Fig. 7. Dorsal inlay urethroplasty

B) Heineke-MikuliczStrictureplasty: HeinekeMikulicz Strictureplasty (HMS) is a urethroplasty technique primarily used for the treatment of largecaliber strictures shorter than $1 \mathrm{~cm}$.HMS does not involve urethral transection and includes lengthwise incision along the stricture and transverse anastomosis (43). In a previous study, Simsek et al. compared EPA and HMS and reported the success rates for the two approaches as $90 \%$ and $80 \%$, respectively (44) (Figure-5).

C) Augmentation Urethroplasty: Augmentation urethroplasty is commonly preferred in the treatment of strictures shorter than 2 cmdue to the formation of ventral cord during erection as a result of urethral shortening performed in EPA (45). Although numerous graft materials have been described in the literature, buccal mucosal graft is the most commonly preferred source of allograftas it is easy to harvest, contains no hair follicles, and is relatively robust (46). There are several approaches described for augmentation urethroplasty, mainly including ventral onlay urethroplasty, ventral dorsal inlay urethroplasty, and dorsal onlay urethroplasty.

-Ventral Onlay Urethroplasty: This approach is performed with the patient placed in the lithotomy position. After the division of the cutaneous and subcutaneous tissue and fascia, the bulbospongiosus muscle is reached and is transected along the midline

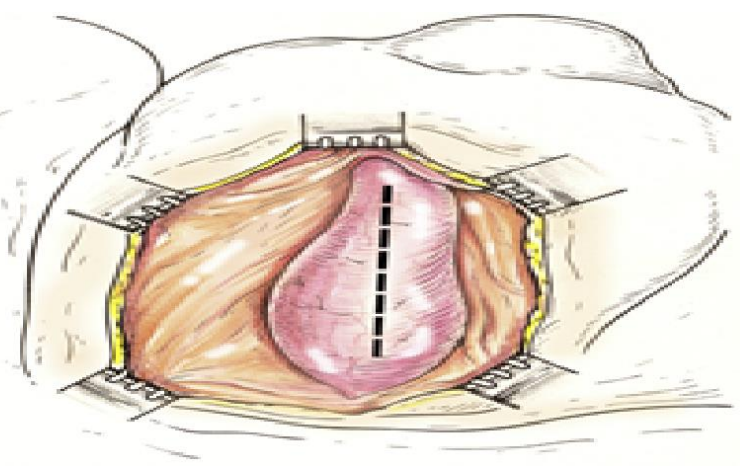

Fig. 6. Ventral Dorsal inlay urethroplasty
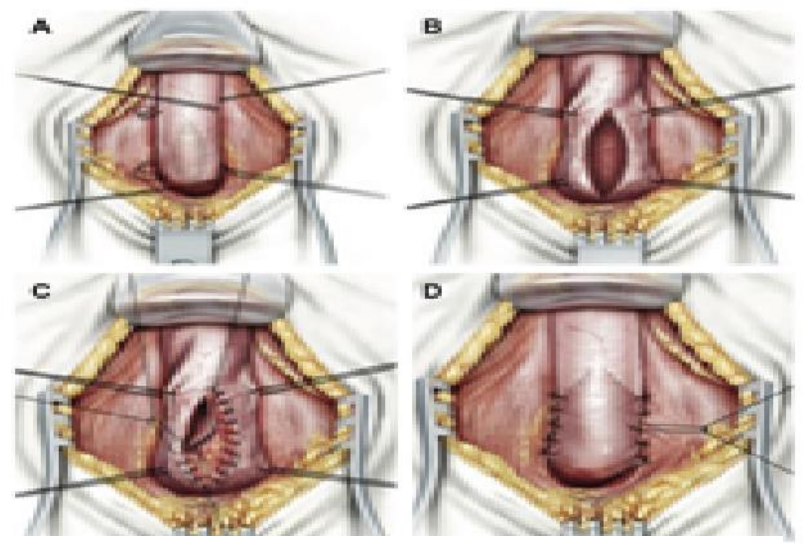

Fig. 8. Dorsal onlay urethroplasty

to expose the urethra. The ventral aspect of the urethra is dissected by a vertical incision and then the graft is placed in the bed. Ventral Onlay Urethroplasty is advantageous as it provides relatively better exposure of proximal anastomotic site and requires less urethral dissection. However, it can also be disadvantageous due to its higher risk of fistula formation associated with itsweaksupport tissue and due to greater blood lossassociated with its large spongious tissue. In patients with radiation-induced urethral strictures, the graft placed on the ventral urethral surface can be supported with the gracilis muscle (47) (Figure-6).

-Ventral Dorsal Inlay Urethroplasty: This approach is performed in the patients with urethroplasty failure that present with difficult urethral mobilization and a thin layer of spongious tissue (Figure-7).

-Dorsal Onlay Urethroplasty: In this approach,which was first described by Barbagli in 1996, the graft is placed on the dorsal surface of the urethra. However, although the graft is fixed on the dorsal surface in the Barbagli approach, it is placed on the dorsolateral surface in the Kulkarni approach (Figure-8). The Kulkarni approach is relatively more advantageous as it does not require complete urethral dissection on the dorsal surface and thus leads to a lower risk of erectile dysfunction and it provides a better visual field. On the other hand, the advantages 
of dorsal and dorsolateral onlay urethroplasty include lower risk of hemorrhage due to the presence of a thin layer of spongious tissue and the posterior support provided by corpus cavernosum. Additionally, its disadvantages include urethral dissection performed on the dorsal surface of the urethra and the difficulty in graft placement (48-50).

Clinical Follow-Up: Patients are often discharged on postoperative day 3 and the urethral and suprapubic catheters are removedon day 21. Ureteroscopy is performed at months 1, 3, 6, and 12 after the removal of the catheters. At each follow-up visit, complete urine examination, uroflowmetry, and postmicturition residual volume measurementshould be performed $(51,52)$.

\section{References}

1. Bhargava S, Chapple CR. Buccal mucosal urethroplasty: is it the new gold standard? BJU Int 2004; 93: 1191-1193.

2. Bhargava S, Chapple CR, Bullock AJ, Layton C, MacNeil S. Tissue-engineered buccal mucosa for substitution urethroplasty. BJU Int 2004; 93: $807-$ 811.

3. Pisapati VL, Paturi S, Bethu S, et al. Dorsal buccal mucosal graft urethroplasty for anterior urethral stricture by Asopa technique. Eur Urol 2009; 56: 201-205.

4. Santucci RA, Joyce GF, Wise M. Male urethral stricture disease. J Urol 2007; 177: 1667-1674.

5. Palminteri E, Berdondini E, Verze $P$, et al. Contemporary urethral stricture characteristics in the developed world. Urology 2013; 81: 191-176.

6. Hampson LA, McAninch JW, Breyer BN. Male urethral strictures and their management. Nat Rev Urol 2014; 11: 43-50.

7. Das S. Urology in ancient India. Indian J Urol 2007; 23: 2-5.

8. Fenton AS, Morey AF, Aviles R, Garcia CR. Anterior urethral strictures: etiology and characteristics. Urology 2005; 65: 1055-1058.

9. Lumen N, Hoebeke P, Willemsen P, Etiology of urethral stricture disease in the 21 st century. J Urol 2009; 182: 983-987.

10. Beard, DE, Goodyear, WE. Urethral stricture: a pathological study. The Journal of Urology 1948; 59: 619-626.

11. Barry MJ, Fowler F, O’Leary M, et al. Correlation of the American Urological Association symptom index with self-administered versions of the Madsen-Iversen, Boyarsky and Maine Medical Assessment Program symptom indexes. The Journal of Urology 1992; 148: 1558-1563.

12. Nuss GR, Geoffrey R, Granierrie M, et al. Presenting symptoms of anterior urethral stricture disease: a disease specific, patient reported questionnaire to measure outcomes. The Journal of Urology 2012; 187: 559-562.
13. Mundy AR, Andrıch DE. Urethral Stricture Review Article Institute of Urology, London, UK. Br J Urol 2012.

14. Jezior J, Jordan GH. Management of bulbous urethral stricture. AUA update series. Eastern Viginia Medical School 2003.

15. Nash P, Peter A, McAninch, et al. Sonourethrography in the evaluation of anterior urethral strictures. The Journal of Urology 1995; 154: 72-76.

16. Morey AF, Mcaninch JW. Ultrasound evaluation of the male urethra for assessment of urethral stricture. Journal of Clinical Ultrasound 1996; 24 : 473-479.

17. Santucci R, E1senberg L. Urethrotomy has a much lower success rate than previously reported. The Journal of Urology 2010; 183: 1859-1862.

18. Albers P, Peter M, fichtner J, et al. Long-term results of internal urethrotomy. The Journal of Urology 1996; 156: 1611-1614.

19. Steenkamp JW, Heyns CF, De Kock MLS. Internal urethrotomy versus dilation as treatment for male urethral strictures: a prospective, randomized comparison. The Journal of Urology 1997; 157: 98-101.

20. Heyns CF, Steencamp J, De Kock et al. Treatment of male urethral strictures: is repeated dilation or internal urethrotomy useful? The Journal of Urology 1998; 160: 356-358.

21. Sachce H. Cystoscopic transurethral incision of urethral stricture with a sharp instrument (author's transl). MMW, Munchener medizinische Wochenschrift 1974; 116: 49: 2147-2150.

22. Hjortrup Allan, Sorensan C, Sanders S. et al. Strictures of the male urethra treated by the Otis method. The Journal of Urology 1983; 130: 903904.

23. Mandhani A, Chaudhury H, Kapoor R, Srivastava A, Dubey D, Kumar A. Can outcome of internal urethrotomy for short segment bulbar urethral stricture be predicted? J Urol 2005; 173: 1595 1597.

24. Dubey D, Kumar A, Mandhani A, Srivastava A, Kapoor R, Bhandari M. Buccal mucosal urethroplasty: a versatile technique for all urethral segments. BJU Int 2005; 95: 625-629.

25. Santucci, R A, Mcaninch, J W. Actuarial success rates of open urethral stricture repair in 369 patients. J Urol 2001; 165.Suppl P: 13.

26. Pansadoro V, Emiliozzı P. Internal urethrotomy in the management of anterior urethral strictures: long-term followup. The Journal of Urology 1996; 156: 73-75.

27. Buckley JC, Heyns C, Gilling P, Carney J. SIU/ICUD Consultation on Urethral Strictures: Dilation, internal urethrotomy, and stenting of male anterior urethral strictures. Urology 2014; 83: 18-22. 
28. Zheng, X Han, Cao D, et al. Comparison between cold knife and laser urethrotomy for urethral stricture: a systematic review and meta-analysis of comparative trials. World Journal of Urology 2019; 1-9.

29. Kumar, Santosh, Kishore, et al. Efficacy of holmium laser urethrotomy and intralesional injection of Santosh PGI tetra-inject (Triamcinolone, Mitomycin C, Hyaluronidase and $\mathrm{N}$-acetyl cysteine) on the outcome of urethral strictures. Central European Journal of Urology 2015; 68: 462.

30. Yildırım A, Mehmet E, Kaynar M, et al. The effectiveness of local steroid injection after internal urethrotomy to avoid recurrence. Archivio Italiano di Urologia e Andrologia 2015; 295-298.

31. Venn SN, Mundy A R. Urethroplasty for balanitis xerotica obliterans. British Journal of Urology 1998; 81: 735-737.

32. Andrich, D E, Mundy, A R. What is the best technique for urethroplasty? European Urology 2008; 54: 1031-1041.

33. Wong, Susan SW, Abuomarzouk O. et al. Simple urethral dilatation, endoscopic urethrotomy, and urethroplasty for urethral stricture disease in adult men. Cochrane Database of Systematic Reviews 2012; 12

34. Iversen Hansen, R, Guldberg, O, Moller, I. Internal urethrotomy with the Sachse urethrotome. Scandinavian Journal of Urology and Nephrology 1981; 15: 189-191.

35. Barbagli, Guido, Kulkarni et al. Long-term followup and deterioration rate of anterior substitution urethroplasty. The Journal of Urology 2014; 192: 808-813.

36. Wright, Jonathan L,Wessels $\mathrm{H}$ et al. What is the most cost-effective treatment for 1 to 2 -cm bulbar urethral strictures: societal approach using decision analysis. Urology 2006; 67: 889-893.

37. Jasionowska, Sara, Bruncchorst et al. Redourethroplasty for the management of recurrent urethral strictures in males: a systematic review. World Journal of Urology 2019; 1-15.

38. Rosenbaum, Clemens M.,Schimid M et al. Redo buccal mucosa graft urethroplasty: success rate, oral morbidity and functional outcomes. BJU international, 2016; 118: 797-803.

39. Eltahawy Ehab A, Virasoro R, et al. Long-term followup for excision and primary anastomosis for anterior urethral strictures. The Journal of urology 2007; 177: 1803-1806.

40. Cooperberg, Matthew R, McAninch J, et al. Urethral reconstruction for traumatic posterior urethral disruption: outcomes of a 25-year experience. The Journal of urology 2007; 178: 2006-2010.

41. Kolukcu E, Beyhan M. Internal Urethrotomy in Patients with Bulbar Urethral Strictures After Transurethral Resection of the Prostate: Is it Reliable? 2019.

42. Morey Allen F, Kizer William S. Proximal bulbar urethroplasty via extended anastomotic approachwhat are the limits?. The Journal of urology 2006; 175: 2145-2149.

43. Lumen Nicolaas, Hoebeke Piet. Oosterlinck, Willem. Ventral longitudinal stricturotomy and transversal closure: the Heineke-Mikulicz principle in urethroplasty. Urology, 2010; 76: 1478-1482.

44. Şimşek A, Şam E, Ekşi M, et al. Kısa Segment Bulbar Üretra Darlıkları İçin Uygulanan Heineke Mikulicz Striktüroplasti ve Uç Uca Anastomotik Üretroplasti Tekniklerinin Karşılaştırılması. Journal of Reconstructive Urology 2017; 7: 102108.

45. Guralnick Michael L, Webster George D. The augmented anastomotic urethroplasty: indications and outcome in 29 patients. The Journal of urology 2001; 165: 1496-1501.

46. Maarouf A.M, Elsayeed R, et al. Buccal versus lingual mucosal graft urethroplasty for complex hypospadias repair. Journal of pediatric urology 2013; 9: 754-758.

47. Elliout Sean P, Metro Michael J, Mcanınch Jack W. Long-term followup of the ventrally placed buccal mucosa onlay graft in bulbar urethral reconstruction. The Journal of urology 2003; 169: 1754-1757.

48. Barbagli Guido, Sansallone S, et al. Current controversies in reconstructive surgery of the anterior urethra: a clinical overview. International braz j urol 2012; 38: 307-316.

49. Singh Bhupendra P, Pathak, Hemant R, Andankar, Mukund G. Dorsolateral onlay urethroplasty for anterior urethral strictures by a unilateral urethral mobilization approach. Indian journal of urology: IJU: journal of the Urological Society of India 2009; 25: 211.

50. Akgül Murat, Kaya Cevdet. Tekrarlayan Bulbar Üretra Darlıkları: Güncel Yaklaşım 93. 2015.

51. Sevinc, C, Balaban M, Ozkaptan O. et al. Salvage urethroplasty using skin grafts for previously failed long-segment urethral strictures. The Kaohsiung journal of medical sciences 2016; 32: 464-468.

52. Javali Tarun Dilip, Katti Amit, Nagaraj Harohalli K. Management of recurrent anterior urethral strictures following buccal mucosal grafturethroplasty: A single center experience. Urology annals 2016; 8: 31. 